\title{
PULMONARY EMBOLISM IN CHILDHOOD
}

BY

\author{
J. M. SMELLIE, M.D., M.R.C.P. \\ (From the Children's Hospital, Birmingham.)
}

Pulmonary embolism in childhood must be an event of extreme rarity, as judged by the number of recorded cases. The following case, which presents several unusual features, appears, therefore, worthy of record.

E. W. B., a male child, aged 9 years, had always enjoyed good health, with the exception of an attack of scarlet fever in 1926. On June 24th, 1929, he went to bed about 10 p.m. apparently perfectly well. He slept with two older brothers. About 1 a.m. on the 25th, a brother noticed that the boy was shivering and cold. About 1.30 a.m. he vomited and complained of thirst. He vomited again at 3.0 a.m. At 5.0 a.m. he was observed to be very pale, but asleep and breathing in a normal fashion. At $9.0 \mathrm{a.m}$. his mother went to him and found him lying on his back in bed. She noticed that he had some yellowish discharge round the mouth and nostrils, and that the bed had been soiled. She wiped away the discharge from the mouth and nose, and as he did not reply when spoken to she thought that he was merely asleep. At 10 a.m. his condition was unchanged, and there was more yellowish fluid being discharged from the mouth and nose. He was pale in the face but appeared to be breathing regularly. As his mother could not rouse him she took him to the Children's Hospital.

On admission to hospital he was profoundly unconscious and died about half an hour later.

An autopsy was performed about six hours after death. The body was that of a wellnourished boy. The thyroid gland was slightly enlarged. The thymus gland weighed 30 grm. and appeared healthy on section. The pleural and pericardial cavities presented no pathological changes. The visceral layer of the pericardium was slightly thickened and opaque, and there were many sub-epicardial petechial hæmorrhages over both anterior and posterior aspects of the heart. There was a large amount of firm ante-mortem clot of an opaque greyish-white colour in the right heart. This thrombus was firmly adherent in one place only, namely, the right auricular appendage, where it was in fact so adherent that it could not be removed without tearing. From this place of origin the thrombus extended through the right auricle, through the tricuspid valve, through the right ventricle and pulmonary valve into the pulmonary artery. It finally terminated in each pulmonary artery just distal to the bifurcation. The thrombus lay entirely free in the artery. There was no endocarditis in either the right or left side of the heart. Both the left auricle and left ventricle contained some agonal clot. On examination of the cut edge of the heart muscle the outer fringe of both the right and left ventricular wall showed changes of cloudy swelling for a depth of approximately $\frac{1}{8}$-inch. The terminal portion of the thrombus in the right pulmonary artery had become dislodged and infarcted in the lower lobe of the right lung. The infarct measured about $3 \mathrm{in}$. in diameter and was rather globular than triangular in shape. It was very hard in consistence : on section it was blackish-red in colour with its margins sharply defined. There were practically no changes to be detected in the over-lying pleura. There were no other infarctions. The brain and abdominal viscera were healthy. There was no thrombosis of any of the venous sinuses within the cranial cavity, and no evident sepsis in the ears, accessory sinuses, tonsils or teeth.

\section{Discussion.}

It is recognized that pulmonary infarction may arise without the production of any of the classical symptoms. In this case it is not possible to say when the infarction actually occurred, but it seems reasonable to presume that when it did occur the pleural and general shock that ensued caused rapid and 
complete loss of consciousness. The yellowish discharge from the mouth and nostrils noticed by the child's mother, was œedematous fluid from the lung, yet death was not due to asphyxia.

As stated previously, the incidence of the condition must be extremely low and such cases as have been recorded were encountered mostly in infants. In 1905 , Pehu and Horand ${ }^{1}$ reported a case in a child aged 6 years, the condition following an aural infection. A similar case in a baby of 7 months was recorded by Guillemot in 1906. In 1913, Lutz ${ }^{3}$ reported six cases, all due either to purulent otitis media or sinus thrombosis. A case in a child aged 4 years was reported by Wessen ${ }^{4}$ in 1921, and last year Stulik and Rust ${ }^{5}$ reported a case in an infant of eleven months, probably due to venous thrombosis in the lower extremities. Thus, of the ten recorded cases seven were in Germany, two in France and one in America. In all these some obvious source of infection appears to have been present.

Thrombosis may arise from a variety of causes. Changes in the composition of the blood, changes in the vessel walls, and mechanical factors causing a disturbance of the circulation are the most important ones. Of these, the third is most frequently met, e.g., the cardiac thromboses that occur in auricular fibrillation and myocardial failure; but in childhood this condition is so rare that it does not need furthor consideration. Changes in the endocardium must therefore take first place, and these changes can only result from inflammation. A review of the macroscopical autopsy findings in my case shows that the epicardium was the seat of a very early acute inflammation, just beginning to involve the myocardium. The distance from the epicardium to the endocardium, that is, the thickness of the heart wall, is least in the auricles, particularly in the auricular appendages, where too the circulation is less strong. By far the most frequent cause of acute infection of the cardiac structures in childhood is acute rheumatism, and, further, this infection may be more virulent and more rapidly fatal than is perhaps generally recognized. I have, for instance, notes of another child, aged 5 years, who died of an acute and extensive rheumatic pan-carditis, with visible endocarditis, after a history of only 36 hours illness.

Blumer ${ }^{6}$ states that all forms of thrombosis are exceedingly rare in rheumatic fever and that cardiac thrombosis, apart from that occurring with a complicating endocarditis and arterial thrombosis, is almost unknown. It is my opinion, however, that the cause of the infection in the case reported here was the streptococcus rheumaticus, but this cannot be definitely astablished as, unfortunately, no histological examinations were made.

\section{REFERENCES.}

1. Peru, M., \& Horand, R., Lyon med., Lyons, 1905, ('IV, 1:307.

2. Guillemot, L., Bull. de la Soc. de pediat., 1906, VIII, 229.

3. Lutz, W., Berlin klin. Wchnschr., Berlin, 1913, L, ii, 1566.

4. Wessen, N., Acta chir., Scandinav., Stockholm, 1921-22, LIV, 123.

5. Stulik, C. K., \& Rust, B. K., Am. J. Dis. Child., Chicago, 1928, XXXVIT, 1246.

6. Blumer, G., Osler \& McCrae, Modern Medicine, 1927, IV, 893. 